\title{
BMJ Open Association between diabetes mellitus and the risk for major cardiovascular outcomes and all-cause mortality in women compared with men: a meta- analysis of prospective cohort studies
}

Hao Wang, Ying Ba, Run-Ce Cai, Qian Xing

To cite: Wang H, Ba Y, Cai R-C, et al. Association between diabetes mellitus and the risk for major cardiovascular outcomes and all-cause mortality in women compared with men: a meta-analysis of prospective cohort studies. BMJ Open 2019;9:e024935. doi:10.1136/ bmjopen-2018-024935

- Prepublication history and additional material for this paper are available online. To view please visit the journal (http:// dx.doi.org/10.1136/bmjopen2018-024935).

Received 21 June 2018 Revised 28 June 2019 Accepted 1 July 2019

\section{Check for updates}

(C) Author(s) (or their employer(s)) 2019. Re-use permitted under CC BY-NC. No commercial re-use. See rights and permissions. Published by BMJ.

First Affiliated Hospital of Dalian Medical University, Dalian, China

Correspondence to

Hao Wang;

wanghaodl@126.com

\section{ABSTRACT}

Objective Previous studies have reported sex differences in associations between diabetes mellitus (DM) and the risk of developing coronary heart disease (CHD) and stroke; however, the risk for cardiac death and all-cause mortality in women compared with men has not been reported. Therefore, this quantitative meta-analysis was performed to provide reliable estimates of sex differences in the effect of DM on major cardiovascular outcomes and all-cause mortality, irrespective of DM type.

Design Meta-analysis.

Data sources The PubMed, Embase and the Cochrane Library databases were systematically searched in April 2018.

Eligibility criteria Investigations designed as prospective cohort studies that examined the association between DM and major cardiovascular outcomes and all-cause mortality stratified according to sex were included.

Data extraction and synthesis Data extraction and quality assessment were independently performed by 2 of the authors, and the relative risk ratio (RRR) obtained using a random effects model was used to measure sex differences in the associations of DM with major cardiovascular outcomes and all-cause mortality. Results Thirty prospective cohort studies that reported data from 1148188 individuals were included. The pooled women-to-men RRR suggested that female sex was associated with an increased risk for CHD (RRR $1.52(95 \% \mathrm{Cl} 1.32$ to 1.76$) ; \mathrm{p}<0.001)$, stroke (RRR $1.23(95 \% \mathrm{Cl} 1.09$ to 1.39$) ; p=0.001)$, cardiac death (RRR 1.49(95\% Cl 1.11 to 2.00); $p=0.009$ ) and all-cause mortality (RRR 1.51(95\% Cl 1.23 to 1.85$) ; p<0.001$ ). In addition, sex differences for the investigated outcomes in the comparison between DM and non-DM patients were variable after stratification of studies according to publication year, country, sample size, assessment of DM, follow-up duration, adjustment for important cardiovascular risk factors and study quality. Conclusions Findings of the present study suggested that women with DM had an extremely high risk for CHD, stroke, cardiac death and all-cause mortality compared with men with DM.
Strengths and limitations of this study

- Published studies with large sample sizes were included in the analysis, and findings of the present study were more robust than those of any individual study.

- All included studies were prospectively designed and population based, which mitigated, if not eliminated, the possibility of uncontrolled biases.

- Large studies with a diverse range of patient characteristics support the generalisability of the results because the populations included were distributed globally.

- Stratified results of sex differences between DM and major cardiovascular outcomes and all-cause mortality were calculated based on the study or patient characteristics.

- Heterogeneity of the included studies was resolved using multiple methods, and no publication bias was found, thus supporting the robustness of the pooled results.

\section{INTRODUCTION}

Cardiovascular disease (CVD) remains the leading cause of morbidity and mortality worldwide and accounts for $10.3 \%$ of the global disease burden, with a mortality rate of approximately $30 \%$ at the first CVD event. ${ }^{2}$ Numerous studies have illustrated the risk for CVD and related factors in various populations. ${ }^{3-7}$ It has been established that the morbidity and mortality of CVD risk are significantly increased in patients with diabetes mellitus (DM).$^{8-11}$ Furthermore, $\mathrm{DM}$ is an independent risk factor for CVD, all-cause mortality, blindness, kidney failure, amputation, fracture, frailty, depression, and cognitive decline, ${ }^{12}$ thus emphasising the need to monitor high risk for CVD in patients with DM.

Sex differences in the effect of DM on the excess risk for coronary heart disease (CHD) 
and stroke have been reported and vary based on several other risk factors. ${ }^{1314}$ These two large-scale quantitative meta-analyses reported that women with DM have a $44 \%$ and $27 \%$ greater risk for CHD and stroke, respectively. Although the mechanism of action remains unclear, the exposure effects may be influenced by non-DM women with persistently healthy lifestyles and are well controlled by other important cardiovascular risk factors. ${ }^{15}$ However, to our knowledge, several other important outcomes, including cardiac death and all-cause mortality, have not been examined in previous studies.

Although previous meta-analyses have illustrated sex differences in the association between DM and CHD and stroke risk, the current study is the first meta-analysis to quantify potential sex differences in cardiac death and all-cause mortality. Clarifying sex differences in DM and major cardiovascular outcomes and all-cause mortality is particularly important to identify high-risk populations for the development of major cardiovascular outcomes and all-cause mortality, given that it has not been definitively determined. Therefore, we performed a large-scale examination of available prospective cohort studies that examined sex-specific effects of DM on the subsequent risk for CHD, stroke, cardiac death and all-cause mortality to determine sex differences in DM regarding major cardiovascular outcomes and all-cause mortality.

\section{MATERIAL AND METHODS}

\section{Data sources, search strategy and selection criteria}

This study was conducted and is reported according to the meta-analysis of observational studies in epidemiology protocol. ${ }^{16}$ Studies with a prospective cohort design that analysed the associations between DM and CHD, stroke, cardiac death and all-cause mortality risk and were published in the English language were potentially eligible for inclusion in this meta-analysis. There were no restrictions on the publication status of the studies considered. Three electronic databases (PubMed, Embase and the Cochrane Library) were searched for studies published from inception to April 2018 using the following search terms: ('diabetes mellitus' OR 'diabetes') AND ('Coronary Disease' OR 'Coronary Artery Disease' OR 'Myocardial Ischemia' OR 'stroke' OR 'death' OR 'mortality') AND ('men' OR 'male') AND ('women' OR 'female') AND ('Cohort Studies' OR 'Prospective Studies') AND 'human' AND 'English'. The details of the strategy used to search PubMed are presented in online supplementary file 1 . Additional eligible studies were identified by manual searches of the reference lists in the relevant original and review articles. The study title, design, exposure, control and outcomes of varying effects in men and women in these studies were separately considered in selecting relevant studies.

The literature search and study selection were performed independently by two reviewers; any disagreement between these reviewers was resolved by including the corresponding author in the discussion until consensus was reached. The inclusion criteria were as follows: design: prospective cohort design; exposure and control: DM (irrespective of DM type) and non-DM; outcomes: CHD, stroke, cardiac death and all-cause mortality; and effect estimate: the relationship between DM and CHD, stroke, cardiac death, and all-cause mortality in men and women were reported separately. Studies examining single-sex populations, those with retrospective observational designs and reported with standard incidence/ mortality ratio were excluded.

\section{Data collection and quality assessment}

Two independent reviewers performed data collection and quality assessment, and any inconsistencies was adjudicated by referring to the original studies. The collected data included the first author or study group's name, publication year, country, sample size, age range, percentage of women, number of DM subjects, assessment of DM, follow-up duration, adjusted factors and investigated outcomes. The effect estimate was selected and maximally adjusted for confounders if the study reported several multivariable adjusted effect estimates. Quality assessment was performed using the Newcastle-Ottawa Scale, which is based on selection (four items), comparability (one item) and outcome (three items). ${ }^{17} \mathrm{~A}$ 'star system' (range: 0-9) was used to evaluate individual study quality.

\section{Statistical analysis}

Sex differences in the relationship between DM and CHD, stroke, cardiac death or all-cause mortality risk were based on the sex-specific effect estimate and corresponding 95\% CI of each individual study. Given the low prevalence of CHD, stroke, cardiac death or all-cause mortality, ORs could be assumed to be accurate estimates of RR. Furthermore, HR was regarded to be equivalent to Relative Risk (RR) in studies with a cohort design. The summary RRs and 95\% CIs for DM versus non-DM and the risk for CHD, stroke, cardiac death and all-cause mortality in men and women were calculated separately using a random-effects model, and the STATA commands were metan lnrr lnrrl lnrru, eform random xlab $(0.3,0.5,1.0$, 2.0) effect (RR) label (namevar=study). ${ }^{18} 19$ The femaleto-male ratio of RRs (ie, relative risk ratio (RRR)) and 95\% CI in each study for CHD, stroke, cardiac death or all-cause mortality were then calculated based on sex-specific RRs and 95\% CIs. ${ }^{14}{ }^{1520}$ Finally, the summary RRR and $95 \%$ CIs for sex differences in DM versus non-DM and CHD, stroke, cardiac death or all-cause mortality risk were calculated using a random-effects model. ${ }^{18} 19$

The $\mathrm{I}^{2}$ and $\mathrm{Q}$ statistics were used to evaluate heterogeneity among the included studies; those with $\mathrm{p}<0.10$ were considered to demonstrate significant heterogeneity. ${ }^{21} 22$ A sensitivity analysis was then conducted to evaluate the impact of individual studies on the overall estimates by excluding each study sequentially. ${ }^{23}$ Subsequently, subgroup analyses for sex differences in DM on CHD, stroke, cardiac death or all-cause mortality risk were 
calculated based on the following: publication year (2010 or after, and before 2010); country (Eastern or Western countries); sample size ( $\geq 10000$ and $<10000)$; assessment of DM (self-reported, measured or both); follow-up duration ( $\geq 10$ and $<10$ years); adjustment for other cardiovascular risk factors (yes or no); and study quality (high vs low). Finally, publication biases for investigated outcomes were assessed using funnel plots, the Egger test and the Begg test. ${ }^{24}{ }^{25}$ Two-sided $p$ values with a significance level of 0.05 were used in the pooled analyses. Statistical analyses were performed using STATA software V.10.0.

\section{Patient and public involvement}

No patients were involved in the development of the research question, outcome measures, design, study implementation, dissemination of the results of the research to the study participants or interpretation of the results.

\section{RESULTS}

\section{Literature search}

The study selection process is shown in online supplementary file 2. A total of 13471 articles were identified in the initial electronic search, of which 12745 were excluded due to duplicates and irrelevant topics. The abstracts of the remaining 726 articles were assessed, and 633 were excluded due to having a design other than prospective cohort and reported cardiovascular risk factors as outcomes. The full text was retrieved for the remaining 93 articles to identify potential studies that may be included. Thirty prospective cohort studies fulfilled the inclusion criteria and were ultimately included in the meta-analysis. $^{26-55}$ There was no additional eligible studies after a manual search of the reference lists of these studies.

\section{Study characteristics}

A total of 30 studies, which included 75 cohorts, 1148188 individuals and $52715 \mathrm{DM}$ patients were included. Table 1 summarises the baseline characteristics of the included studies. The follow-up period was 5.0-30.0 years, while 787-436832 individuals were included in each study. Forty-one cohorts were from countries in the Western countries, and the remaining 34 from the Eastern countries. The percentage of women ranged from $33.0 \%$ to $63.0 \%$. Nine studies used self-reported methods to assess DM, 16 studies used medical methods and the remaining 5 used both self-reported and medical methods. Overall, 9 studies had a Newcastle-Ottawa Scale score of 8, 12 studies had a score of 7 and the remaining 9 studies had a score of 6 (online supplementary file 3 ).

\section{Coronary heart disease}

Twenty studies reported sex differences in the association between DM and subsequent CHD risk. Summaries of the results in men and women are shown separately in online supplementary file 4 . The results indicated that DM was associated with an increased risk for CHD risk in both men and women. Furthermore, the pooled RRR (female to male) of DM versus non-DM and the risk for CHD was 1.52 (95\% CI 1.32 to $1.76 ; \mathrm{p}<0.001$ ) (figure $1 \mathrm{~A}$ ). Although the difference was statistically significant, there was significant heterogeneity among the studies $\left(\mathrm{I}^{2}=36.1 \% ; \mathrm{p}=0.044\right)$. Results of the sensitivity analysis were not affected after sequential exclusion of each study from the pooled analyses (online supplementary file 5). The results of subgroup analyses were consistent with the overall analysis in most subsets, except for follow-up duration $<10.0$ years (table 2 ).

\section{Stroke}

Twenty studies reported sex differences in the association between DM and subsequent risk for stroke. The pooled results in men and women with DM were statistically significant (online supplementary file 4). The pooled RRR (female to male) suggested that women with DM had an increased risk for stroke compared with men with DM (RRR 1.23 (95\% CI 1.09 to 1.39); $\mathrm{p}=0.001$ ) (figure 1B), and no evidence of heterogeneity was observed $\left(\mathrm{I}^{2}=0.0 \%\right.$; $\mathrm{p}=0.568$ ). Sensitivity analysis indicated that the conclusion was not affected by sequential exclusion of each study from the pooled analyses (online supplementary file 5). Subgroup analysis indicated no sex differences in the relationship between DM and stroke risk for pooled studies published in 2010 or after, conducted in the Eastern hemisphere, sample sizes $<10000$, those that used both self-reported and measured parameters, duration of follow-up $<10.0$ years, no adjustments for other cardiovascular risk factors and those of low quality (table 3).

\section{Cardiac death}

Ten cohort studies reported sex differences in the association between DM and subsequent risk for cardiac death. DM was associated with a greater risk for cardiac death in men and women independently (online supplementary file 4). The pooled RRR (female to male) of DM versus non-DM for risk for cardiac death was 1.49 (95\% CI 1.11 to 2.00; $\mathrm{p}=0.009$ ) (figure 2A), which was a statistically significant difference; furthermore, non-significant heterogeneity was detected $\left(I^{2}=31.9 \% ; p=0.153\right)$. Results of the sensitivity analysis were altered after excluding the Kuopio and North Karelia studies (online supplementary file 5). Subgroup analysis indicated significant sex differences in DM in cardiac death if the study was published before 2010, was conducted in the Western hemisphere, had a sample size $\geq 10000$, used medical measures to assess DM, had a follow-up duration $\geq 10.0$ years, was adjusted for other cardiovascular risk factors and was of high quality (table 4).

\section{All-cause mortality}

Seven cohort studies reported sex differences in the association between DM and subsequent all-cause mortality risk. Results indicated that DM was associated with a higher risk for all-cause mortality in men and women independently (online supplementary file 4 ). The pooled 


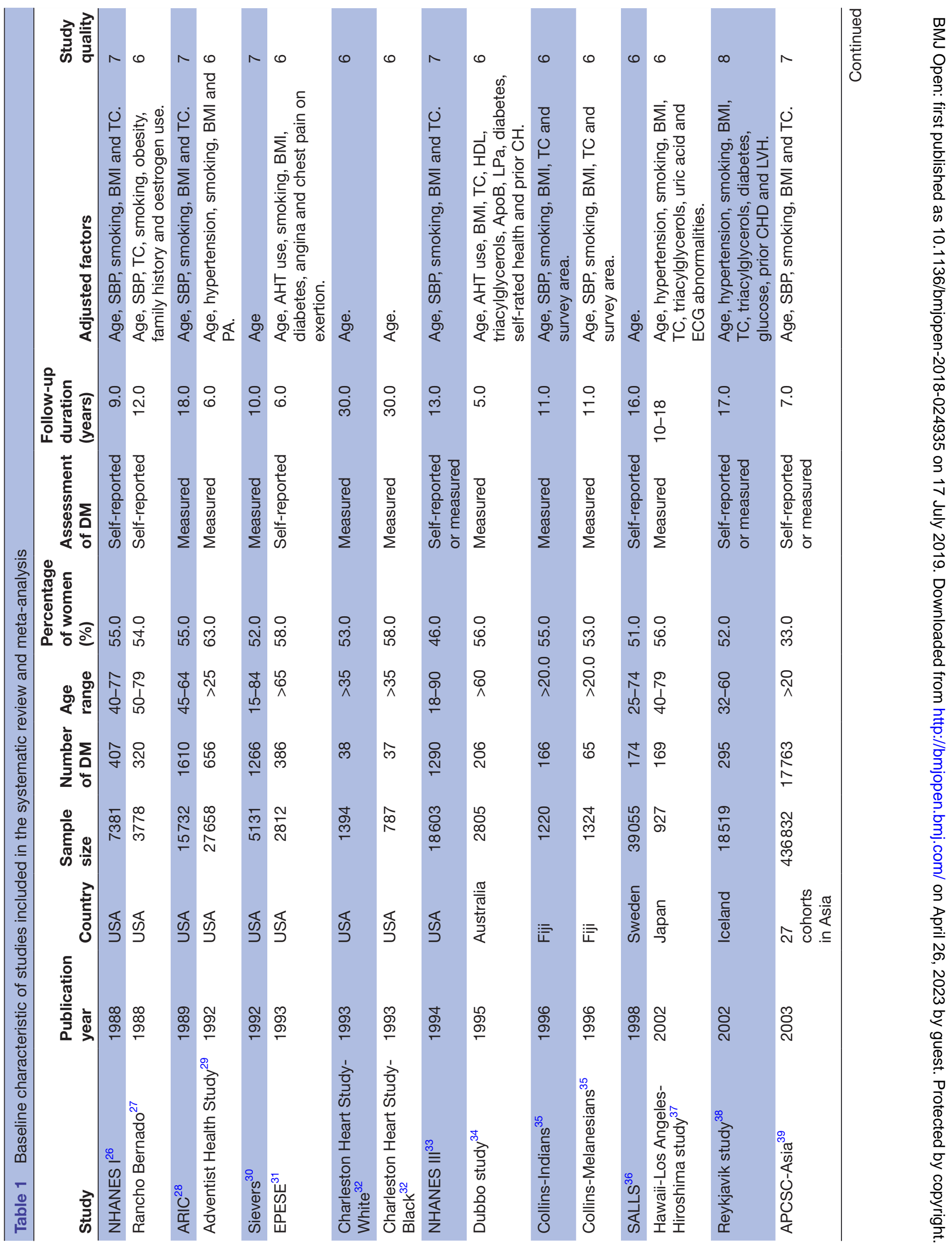




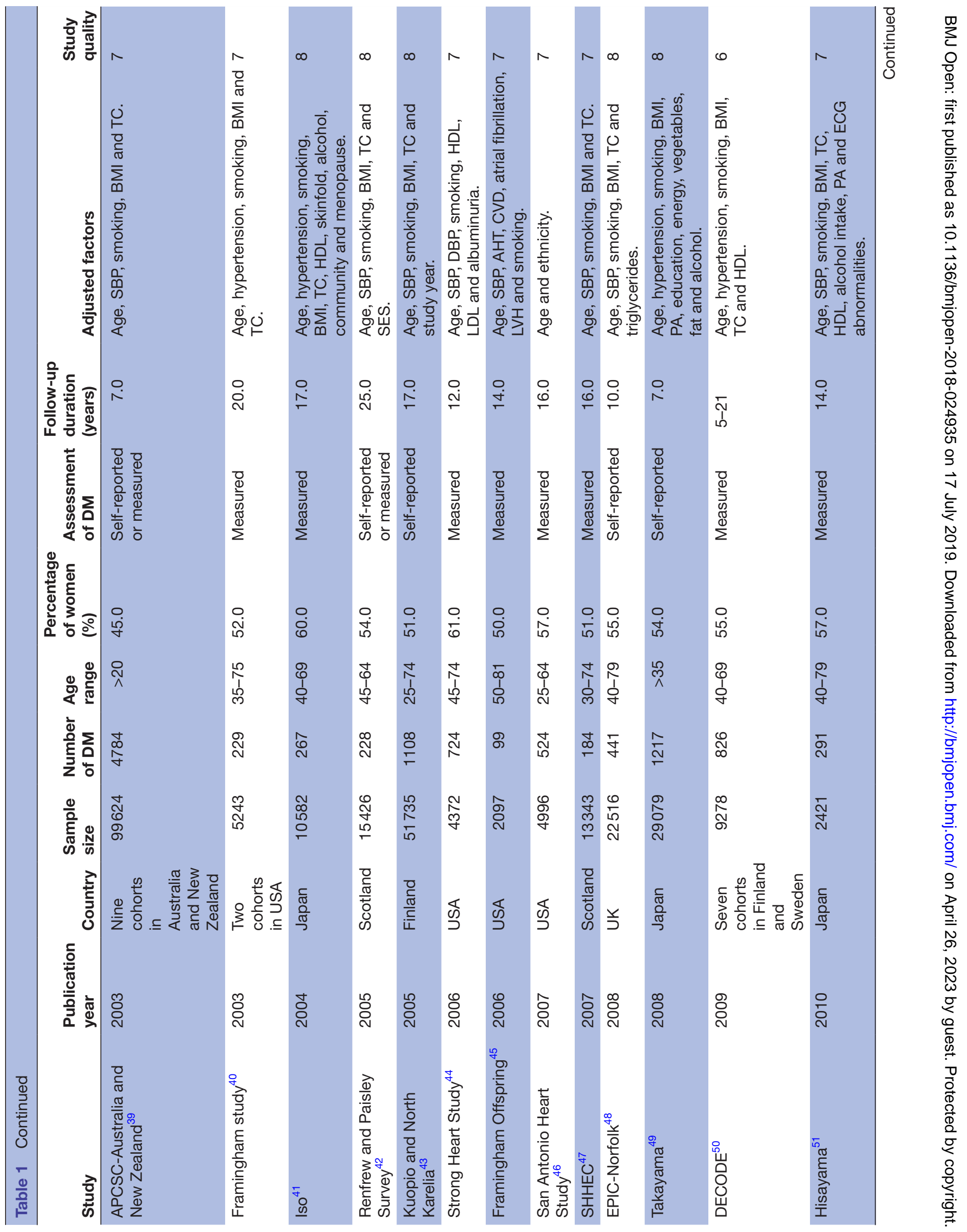




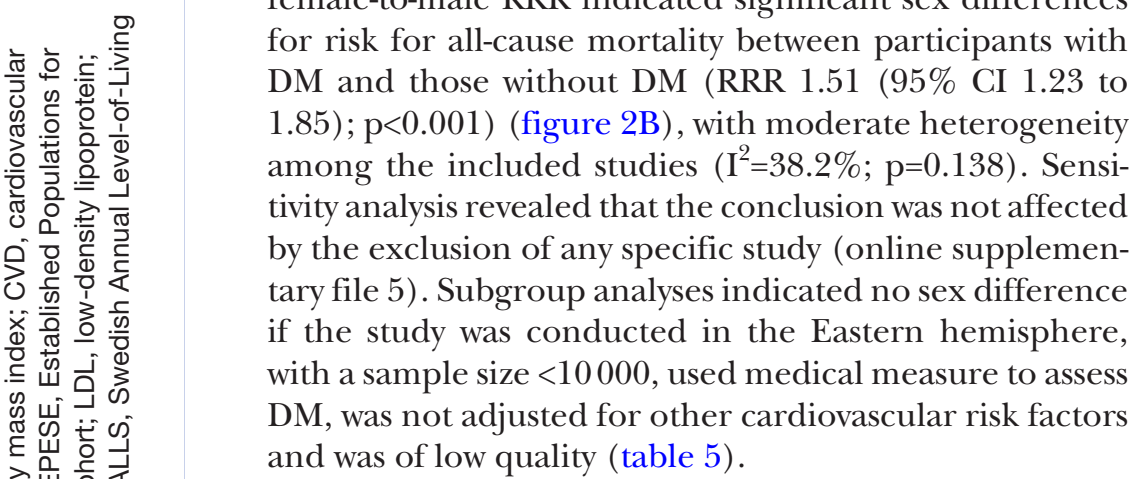

\section{Publication bias}

A review of the funnel plots could not rule out the potential for publication bias for CHD, stroke, cardiac death and all-cause mortality (online supplementary file 6). The Egger and Begg test results revealed no evidence of publication bias for CHD (Egger $\mathrm{p}=0.959$; Begg $\mathrm{p}=0.245$ ), stroke (Egger $\mathrm{p}=0.407$; Begg $\mathrm{p}=0.398$ ), cardiac death (Egger $\mathrm{p}=0.418$; Begg $\mathrm{p}=0.721$ ) and all-cause mortality (Egger $\mathrm{p}=0.118$; Begg $\mathrm{p}=0.230$ ).

\section{DISCUSSION}

The current investigation was based on a collection of prospective cohort studies and explored all possible sex differences between DM and the outcomes of CHD, stroke, cardiac death and all-cause mortality. This large quantitative study included 1148188 individuals and 52715 DM patients from 30 prospective cohort studies investigating a broad range of populations. Findings from the current meta-analysis suggest that there are significant sex differences in DM versus non-DM regarding the incidence of CHD, stroke, cardiac death, all-cause mortality, with women demonstrating excessively higher risks than men. Furthermore, the findings of subgroup analyses could have been biased by publication year, country, sample size, assessment of DM, follow-up duration, adjustment for important cardiovascular risk factors and study quality.

Previous studies have suggested that women with DM have an increased risk for CHD or stroke compared with men with DM. ${ }^{13} 14$ One of these investigations reported that the incidence of CHD was $44 \%$ greater in women with DM than in men with DM. ${ }^{13}$ Moreover, women with DM exhibited an increased risk for stroke compared with men with DM. ${ }^{14}$ However, sex differences regarding other important outcomes (cardiac death and all-cause mortality) were not evident. Therefore, we conducted this comprehensive quantitative meta-analysis of available prospective cohort studies to evaluate sex differences in DM and possible associations with major cardiovascular outcomes. Similar to previous meta-analyses, a significantly increased risk for cardiac death and all-cause mortality was observed in women with DM compared with men with DM. The excess risk for cardiac death in women with DM could be due to the higher risk for CHD 


\begin{tabular}{|c|c|c|c|c|c|}
\hline study & $\operatorname{rrr}(95 \% \mathrm{Cl})$ & \%eight & study & $\operatorname{rrr}(95 \% \mathrm{Cl})$ & Weight \\
\hline Charleston Heart Study-Black & $0.81(0.09,7) 16$ & 0.43 & Collins-Indians & $0.13(0.01,1.61)$ & 0.23 \\
\hline Framingham study & $0.89(0.32,2.41)$ & 1.81 & Takayama & $0.53(0.19,1.50)$ & 1.35 \\
\hline Advantist Health Study & $1.02(0.46,2) 26$ & 2.69 & DECODE & $0.79(0.41,1.51)$ & 3.40 \\
\hline Dubbo study & $1.09(0.60,1.97)$ & 4.27 & Hisayama & $0.80(0.33,1.90)$ & 1.88 \\
\hline NHANESI & $1.09(0.57,2.09)$ & 3.73 & APCSC-ANZ & $0.87(0.53,1.44)$ & 5.66 \\
\hline DECODE & $1.19(0.73,1.93)$ & 5.52 & ESPro & $0.88(0.61,1.26)$ & 10.69 \\
\hline Charleston Heart Study-White & $1.19(0.26,5.49)$ & 0.84 & NHANES III & $1.13(0.41,3.16)$ & 1.37 \\
\hline SHHEC & $1.23(0.78,1.93)$ & 6.06 & Rancho Bernado & $1.22(0.47,3.16)$ & 1.59 \\
\hline APCSC-Asia & $1.24(0.66,2.32)$ & 3.89 & Iso & $1.22(0.53,2.82)$ & 2.05 \\
\hline APCSC-ANZ & $1.27(0.93,1.75)$ & 8.72 & JACC & $1.28(0.96,1.70)$ & 17.70 \\
\hline Strong Heart Study & $1.36(0.95,1) 96$ & 7.69 & SHHEC & $1.30(0.68,2.50)$ & 3.36 \\
\hline HUNT 1 & $1.39(1.14,1.69)$ & 11.71 & JPHC & $1.34(0.84,2.14)$ & 6.51 \\
\hline JACC & $1.40(0.97,2.00)$ & 7.77 & APCSC-Asia & $1.35(0.98,1.87)$ & 13.59 \\
\hline San Antonio Heart Study & $\begin{array}{l}1.46(0.32,6.71) \\
166(0.99,279)\end{array}$ & $\begin{array}{l}0.84 \\
5.14\end{array}$ & SALLS & $1.39(0.79,2.45)$ & 4.43 \\
\hline $\begin{array}{l}\text { Reykjavik study } \\
\text { Renfrew and Paisley Survey }\end{array}$ & $1.68(0.93,3) 06$ & $\begin{array}{l}3.14 \\
4.19\end{array}$ & Framingham Offspring & $1.40(0.32,6.04)$ & 0.67 \\
\hline EPESE & $1.83(0.69,4.88)$ & 1.88 & EPIC-Norfolk & $1.46(0.65,3.31)$ & 2.15 \\
\hline Hawaii-Los Angeles-Hiroshima study & $2.14(1.00,4) 56$ & 2.92 & Kuopio and North Karelia & $1.47(0.86,2.51)$ & 5.00 \\
\hline Kuopio and North Karelia & $2.32(1.67,3.21)$ & 8.49 & Dubbo study & $1.53(0.66,3.53)$ & 2.05 \\
\hline Hisayama & $2.75(1.01,7) 46$ & 1.83 & Collins-Melanesians & $1.54(0.15,15.57)$ & 0.27 \\
\hline SALLS & $2.78(2.02,3.82)$ & 8.70 & ARIC & $1.58(1.15,2.18)$ & 13.85 \\
\hline Collins-Melanesians & $3.35(0.45,24,86$ & 0.50 & Renfrew and Paisley Survey & $1.86(0.74,4.71)$ & 1.66 \\
\hline Collins-Indians & $6.57(0.66,65.00)$ & 0.39 & Sievers & $2.88(0.57,14.46)$ & 0.55 \\
\hline Overall $(I-$ squared $=36.1 \%, p=0.044)$ & $1.52(1.32,1.76)$ & 100.00 & Overall (I-squared $=0.0 \%, \mathrm{p}=0.568)$ & $\begin{array}{l}1.23(1.09,1.39) \\
P=0.001\end{array}$ & 100.00 \\
\hline NOTE: Weights are from random effects analysis & $P<0.001$ & & NOTE: Weights are from random effects analysis & & \\
\hline
\end{tabular}

Figure 1 Sex differences in the associations between diabetes mellitus (DM) and the risk for coronary heart disease (CHD) (A) and stroke (B).

in women with DM, which may be due to the fact that women with DM have a greater adverse cardiovascular risk and are less likely to achieve recommended levels compared with men with DM. Cardiac death, as a part of CHD and the sex difference in the relationship between DM and CHD, was addressed in a previous meta-analysis. ${ }^{13}$ The death events were mostly caused by CVD in most of the included cohorts and may explain the significant sex differences in the association between DM and all-cause mortality. Finally, the respective control group in men and women with different cardiovascular risk, which could affect sex differences in the associations between DM and cardiac death and all-cause mortality.

Findings from the subgroup analysis suggested that sex differences in the relationship between DM and major cardiovascular outcomes and all-cause mortality may vary according to predefined factors. First, publication year affected sex differences in the risk for stroke, which may

Table 2 Subgroup analyses for CHD

\begin{tabular}{|c|c|c|c|c|c|c|c|}
\hline Variable & Group & $\begin{array}{l}\text { Number of } \\
\text { cohorts }\end{array}$ & RRR and $95 \% \mathrm{Cl}$ & $P$ value & $I^{2}(\%)$ & $\begin{array}{l}\mathbf{P} \text { value for } \\
\text { heterogeneity }\end{array}$ & $\begin{array}{l}\text { P value } \\
\text { for meta- } \\
\text { regression }\end{array}$ \\
\hline \multirow[t]{2}{*}{ Publication year } & Before 2010 & 20 & 1.53 (1.28 to 1.82$)$ & $<0.001$ & 39.6 & 0.036 & 0.260 \\
\hline & 2010 or after & 3 & 1.42 (1.20 to 1.68$)$ & $<0.001$ & 0.0 & 0.421 & \\
\hline Country & Western & 18 & 1.50 (1.27 to 1.77$)$ & $<0.001$ & 43.6 & 0.025 & 0.934 \\
\hline Sample size & $<10000$ & 14 & 1.34 (1.09 to 1.63$)$ & 0.004 & 0.0 & 0.780 & \\
\hline \multirow[t]{3}{*}{ Assessment of DM } & Self-reported & 6 & 1.75 (1.29 to 2.37$)$ & $<0.001$ & 74.6 & 0.001 & 0.073 \\
\hline & Measured & 13 & 1.32 (1.09 to 1.61$)$ & 0.005 & 0.0 & 0.764 & \\
\hline & Both & 4 & 1.39 (1.11 to 1.75$)$ & 0.005 & 0.0 & 0.730 & \\
\hline $\begin{array}{l}\text { Adjusted other } \\
\text { CVD risk factors }\end{array}$ & No & 4 & 2.56 (1.89 to 3.46$)$ & $<0.001$ & 0.0 & 0.423 & \\
\hline \multirow[t]{2}{*}{ Study quality } & High & 13 & 1.46 (1.29 to 1.66$)$ & $<0.001$ & 10.6 & 0.339 & 0.052 \\
\hline & Low & 10 & 1.64 (1.14 to 2.36$)$ & 0.007 & 47.8 & 0.045 & \\
\hline
\end{tabular}

CVD, cardiovascular disease. 
Table 3 Subgroup analyses for stroke

\begin{tabular}{|c|c|c|c|c|c|c|c|}
\hline Variable & Group & $\begin{array}{l}\text { Number of } \\
\text { cohorts }\end{array}$ & RRR and $95 \% \mathrm{Cl}$ & $P$ value & $I^{2}(\%)$ & $\begin{array}{l}\text { P value for } \\
\text { heterogeneity }\end{array}$ & $\begin{array}{l}P \text { value } \\
\text { for meta- } \\
\text { regression }\end{array}$ \\
\hline \multirow[t]{2}{*}{ Publication year } & Before 2010 & 18 & 1.29 (1.11 to 1.50$)$ & 0.001 & 0.0 & 0.640 & 0.269 \\
\hline & 2010 or after & 4 & $1.11(0.89$ to 1.40$)$ & 0.353 & 18.1 & 0.300 & \\
\hline \multirow[t]{2}{*}{ Country } & Western & 15 & 1.23 (1.05 to 1.44$)$ & 0.011 & 0.0 & 0.587 & 0.998 \\
\hline & Eastern & 7 & 1.20 (0.97 to 1.49$)$ & 0.091 & 14.7 & 0.318 & \\
\hline \multirow[t]{2}{*}{ Sample size } & $\geq 10000$ & 14 & 1.25 (1.10 to 1.42$)$ & $<0.001$ & 0.0 & 0.531 & 0.341 \\
\hline & $<10000$ & 8 & 1.04 (0.72 to 1.50$)$ & 0.840 & 0.0 & 0.493 & \\
\hline \multirow{3}{*}{$\begin{array}{l}\text { Assessment of } \\
\text { DM }\end{array}$} & Self-reported & 6 & 1.28 (1.04 to 1.58$)$ & 0.022 & 0.0 & 0.668 & 0.423 \\
\hline & Measured & 11 & $1.32(1.08$ to 1.61$)$ & 0.008 & 0.0 & 0.508 & \\
\hline & Both & 5 & 1.09 (0.85 to 1.41$)$ & 0.484 & 21.3 & 0.279 & \\
\hline \multirow{2}{*}{$\begin{array}{l}\text { Follow-up } \\
\text { duration (years) }\end{array}$} & $\geq 10$ & 18 & 1.28 (1.11 to 1.47$)$ & 0.001 & 0.0 & 0.726 & 0.313 \\
\hline & $<10$ & 4 & 1.09 (0.76 to 1.57$)$ & 0.627 & 36.0 & 0.196 & \\
\hline \multirow{2}{*}{$\begin{array}{l}\text { Adjusted other } \\
\text { CVD risk factors }\end{array}$} & Yes & 19 & 1.27 (1.11 to 1.44$)$ & $<0.001$ & 0.0 & 0.695 & 0.237 \\
\hline & No & 3 & $1.14(0.71$ to 1.83$)$ & 0.586 & 40.4 & 0.187 & \\
\hline \multirow[t]{2}{*}{ Study quality } & High & 16 & 1.24 (1.09 to 1.41$)$ & 0.001 & 0.0 & 0.533 & 0.617 \\
\hline & Low & 6 & 1.13 (0.79 to 1.61$)$ & 0.498 & 2.4 & 0.401 & \\
\hline
\end{tabular}

CVD, cardiovascular disease; RRR, relative risk ratio.

be due to advances in diagnostic approaches. Second, country (ie, hemisphere) could affect sex differences in DM and the risk for cardiac death and all-cause mortality, which could be explained by differences in the prevalence of cardiac death and all-cause mortality Eastern and Western countries. Third, sample size affected sex differences in the risk for stroke, cardiac death and all-cause mortality due to sample sizes being correlated with statistical power, which may have affected the ability to detect small differences. Fourth, the methods of assessing DM could affect sex differences in stroke, cardiac death and all-cause mortality because they may affect the prevalence of event rates. Fifth, follow-up duration could affect sex differences in the risk for CHD, stroke and cardiac death, because there were studies with longer follow-up and higher proportion of patients with CHD than studies with shorter follow-up, which contributed to the higher weight in pooled results and made it easier to detect small

\begin{tabular}{llll} 
study & & & \\
Wrr $(95 \% \mathrm{Cl})$ & Weight \\
\hline Hawaii-Los Angeles-Hiroshima study (a) & $0.75(0.19,2.95)$ & 4.11 \\
Advantist Health Study & $0.83(0.40,1.73)$ & 11.34 \\
Collins-Indians & $0.84(0.29,2.42)$ & 6.47 \\
Hawaii-Los Angeles-Hiroshima study (b) & $1.04(0.62,1.75)$ & 17.16 \\
Renfrew and Paisley Survey & $1.68(0.93,3.06)$ & 14.68 \\
San Antonio Heart Study (b) & $1.74(0.51,5.97)$ & 4.98 \\
Kuopio and North Karelia & $2.01(1.55,2.62)$ & 28.51 \\
Collins-Melanesians & $2.29(0.68,7.74)$ & 5.06 \\
EPESE & $2.88(0.87,9.61)$ & 5.18 \\
San Antonio Heart Study (a) & $3.54(0.58,21.45)$ & 2.51 \\
Overall (I-squared = 31.9\%, $\mathrm{p}=0.153)$ & $1.49(1.11,2.00)$; & 100.00 \\
NOTE: Weights are from random effects analysis & & & \\
\hline
\end{tabular}

A. cardiac death

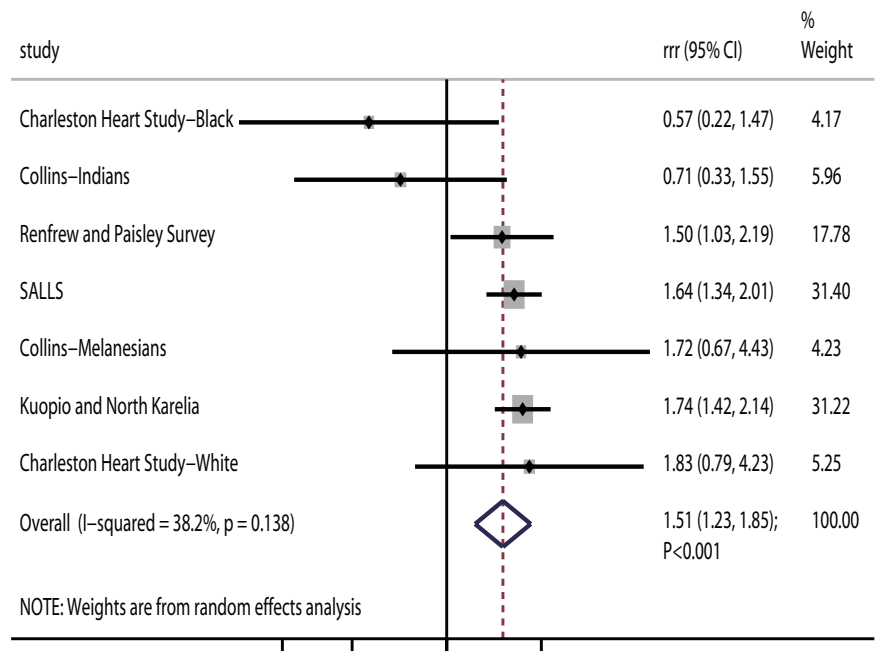

B. all-cause mortality

Figure 2 Sex differences in the associations between diabetes mellitus (DM) and the risk for cardiac death (A) and all-cause mortality (B). 
Table 4 Subgroup analyses for cardiac death

\begin{tabular}{|c|c|c|c|c|c|c|c|}
\hline Variable & Group & $\begin{array}{l}\text { Number of } \\
\text { cohorts }\end{array}$ & RRR and $95 \% \mathrm{Cl}$ & $P$ value & $\mathrm{I}^{2}(\%)$ & $\begin{array}{l}\text { P value for } \\
\text { heterogeneity }\end{array}$ & $\begin{array}{l}\text { P value } \\
\text { for meta- } \\
\text { regression }\end{array}$ \\
\hline \multirow[t]{2}{*}{ Publication year } & Before 2010 & 10 & 1.49 ( 1.11 to 2.00$)$ & 0.009 & 31.9 & 0.153 & - \\
\hline & 2010 or after & 0 & - & - & - & - & \\
\hline \multirow[t]{2}{*}{ Country } & Western & 7 & 1.84 (1.45 to 2.32 ) & $<0.001$ & 3.6 & 0.399 & 0.010 \\
\hline & Eastern & 3 & 0.97 (0.62 to 1.51$)$ & 0.891 & 0.0 & 0.870 & \\
\hline \multirow[t]{2}{*}{ Sample size } & $\geq 10000$ & 2 & 1.96 (1.54 to 2.49 ) & $<0.001$ & 0.0 & 0.591 & 0.015 \\
\hline & $<10000$ & 8 & 1.18 (0.85 to 1.64$)$ & 0.322 & 0.0 & 0.433 & \\
\hline \multirow{3}{*}{$\begin{array}{l}\text { Assessment of } \\
\text { DM }\end{array}$} & Self-reported & 2 & 2.05 (1.59 to 2.64 ) & $<0.001$ & 0.0 & 0.568 & 0.016 \\
\hline & Measured & 7 & 1.10 (0.78 to 1.54$)$ & 0.588 & 0.0 & 0.586 & \\
\hline & Both & 1 & 1.68 (0.93 to 3.06$)$ & 0.087 & - & - & \\
\hline \multirow{2}{*}{$\begin{array}{l}\text { Follow-up } \\
\text { duration (years) }\end{array}$} & $\geq 10$ & 8 & 1.57 (1.18 to 2.09 ) & 0.002 & 21.8 & 0.256 & 0.257 \\
\hline & $<10$ & 2 & 1.41 (0.42 to 4.68$)$ & 0.576 & 66.5 & 0.084 & \\
\hline \multirow{2}{*}{$\begin{array}{l}\text { Adjusted other } \\
\text { CVD risk factors }\end{array}$} & Yes & 8 & 1.42 (1.02 to 1.98$)$ & 0.040 & 44.0 & 0.085 & 0.575 \\
\hline & No & 2 & 2.18 (0.79 to 6.03 ) & 0.132 & 0.0 & 0.524 & \\
\hline \multirow[t]{2}{*}{ Study quality } & High & 4 & 1.97 ( 1.56 to 2.48 ) & $<0.001$ & 0.0 & 0.864 & 0.006 \\
\hline & Low & 6 & 1.10 (0.78 to 1.55$)$ & 0.593 & 0.0 & 0.417 & \\
\hline
\end{tabular}

CVD, cardiovascular disease; DM, diabetes mellitus.

differences. Finally, the other major cardiovascular risk factors, regardless of whether they were adjusted for, and study quality affected sex differences in stroke, cardiac death and all-cause mortality. Pooled studies with high quality or those that adjusted for other cardiovascular risk factors could have obtained more reliable results.

Several strengths of this meta-analysis should be highlighted. First, given the comprehensive inclusion of

Table 5 Subgroup analyses for all-cause mortality

\begin{tabular}{|c|c|c|c|c|c|c|c|c|}
\hline Outcomes & Variable & Group & $\begin{array}{l}\text { Number of } \\
\text { cohorts }\end{array}$ & RRR and $95 \% \mathrm{Cl}$ & $P$ value & $I^{2}(\%)$ & $\begin{array}{l}P \text { value for } \\
\text { heterogeneity }\end{array}$ & $\begin{array}{l}P \text { value } \\
\text { for meta- } \\
\text { regression }\end{array}$ \\
\hline \multirow{15}{*}{$\begin{array}{l}\text { All-cause } \\
\text { mortality }\end{array}$} & \multirow{2}{*}{$\begin{array}{l}\text { Publication } \\
\text { year }\end{array}$} & Before 2010 & 7 & 1.51 (1.23 to 1.85$)$ & $<0.001$ & 38.2 & 0.138 & - \\
\hline & & 2010 or after & 0 & - & - & - & - & \\
\hline & \multirow[t]{2}{*}{ Country } & Western & 6 & 1.63 (1.41 to 1.88$)$ & $<0.001$ & 8.2 & 0.364 & 0.039 \\
\hline & & Eastern & 1 & 0.71 (0.33 to 1.55$)$ & 0.394 & - & - & \\
\hline & \multirow[t]{2}{*}{ Sample size } & $\geq 10000$ & 3 & 1.66 (1.46 to 1.90$)$ & $<0.001$ & 0.0 & 0.772 & 0.050 \\
\hline & & $<10000$ & 4 & 1.06 (0.59 to 1.90$)$ & 0.844 & 43.7 & 0.149 & \\
\hline & \multirow{3}{*}{$\begin{array}{l}\text { Assessment } \\
\text { of DM }\end{array}$} & Self-reported & 2 & 1.69 (1.46 to 1.95$)$ & $<0.001$ & 0.0 & 0.669 & 0.123 \\
\hline & & Measured & 4 & 1.06 (0.59 to 1.90$)$ & 0.844 & 43.7 & 0.149 & \\
\hline & & Both & 1 & 1.50 (1.03 to 2.19$)$ & 0.035 & - & - & \\
\hline & \multirow{2}{*}{$\begin{array}{l}\text { Follow-up } \\
\text { duration } \\
\text { (years) }\end{array}$} & $\geq 10$ & 7 & 1.51 (1.23 to 1.85$)$ & $<0.001$ & 38.2 & 0.138 & - \\
\hline & & $<10$ & 0 & - & - & - & - & \\
\hline & \multirow{2}{*}{$\begin{array}{l}\text { Adjusted } \\
\text { other CVD } \\
\text { risk factors }\end{array}$} & Yes & 4 & 1.50 (1.12 to 2.01$)$ & 0.006 & 39.4 & 0.176 & 0.850 \\
\hline & & No & 3 & 1.33 (0.75 to 2.36$)$ & 0.321 & 57.6 & 0.095 & \\
\hline & \multirow[t]{2}{*}{ Study quality } & High & 2 & 1.69 (1.41 to 2.02$)$ & $<0.001$ & 0.0 & 0.490 & 0.414 \\
\hline & & Low & 5 & 1.25 (0.80 to 1.94$)$ & 0.329 & 53.3 & 0.073 & \\
\hline
\end{tabular}

CVD, cardiovascular disease; DM, diabetes mellitus. 
published studies with large sample sizes, the findings of the present study were more robust than any of those individual studies. Second, all studies included were prospectively designed and population based, which could mitigate-if not eliminate-uncontrolled biases. Third, large-scale studies including patients with a broad range of characteristics support the generalisability of the results given the global distribution of the included populations. Fourth, stratified results of sex differences in DM and major cardiovascular outcomes based on study or patient characteristics were calculated. Finally, heterogeneity among the included studies was resolved using multiple methods, and no publication bias was found, which supports the robustness of the pooled results.

However, several limitations of this meta-analysis should also be acknowledged. First, various adjustments for cardiovascular risk factors across the included studies may have affected the development of major cardiovascular outcomes, as would various DM types, DM assessment methods and the duration of DM. Publication bias is inevitable when searching databases given the variation in publication languages, and the number of published studies with negative results. Finally, data regarding background drug use were available in few studies, which may have affected the absolute risk for major cardiovascular outcomes.

In conclusion, the results of this study indicated that women with DM exhibited a greater risk for CHD, stroke, cardiac death and all-cause mortality compared with men with DM. Furthermore, the true sex differences for the association between DM and major cardiovascular outcomes was variable and based on several characteristics of the study or the patients involved. Sex differences in specific patient characteristics should be verified and clarified, along with other biological, behavioural or social factors in future larger-scale prospective studies.

Contributors HW contributed to conception and design; all authors contributed to acquisition, analysis and interpretation of data; HW and QX were involved in drafting or critical revision of the manuscript. All the authors approved the final version.

Funding The authors have not declared a specific grant for this research from any funding agency in the public, commercial or not-for-profit sectors.

Competing interests None declared.

Patient consent for publication Not required.

Provenance and peer review Not commissioned; externally peer reviewed.

Data sharing statement No additional data available.

Open access This is an open access article distributed in accordance with the Creative Commons Attribution Non Commercial (CC BY-NC 4.0) license, which permits others to distribute, remix, adapt, build upon this work non-commercially, and license their derivative works on different terms, provided the original work is properly cited, appropriate credit is given, any changes made indicated, and the use is non-commercial. See: http://creativecommons.org/licenses/by-nc/4.0/.

\section{REFERENCES}

1. Yusuf S, Reddy S, Ounpuu S, et al. Global burden of cardiovascular diseases: part I: general considerations, the epidemiologic transition, risk factors, and impact of urbanization. Circulation 2001;104:2746-53.
2. Chambless L, Keil U, Dobson A, et al. Population versus clinical view of case fatality from acute coronary heart disease: results from the WHO MONICA Project 1985-1990. Multinational MONItoring of Trends and Determinants in CArdiovascular Disease. Circulation 1997;96:3849-59.

3. Odutayo A, Wong CX, Hsiao AJ, et al. Atrial fibrillation and risks of cardiovascular disease, renal disease, and death: systematic review and meta-analysis. BMJ 2016;354:i4482.

4. Mente A, O'Donnell M, Rangarajan S, et al. Associations of urinary sodium excretion with cardiovascular events in individuals with and without hypertension: a pooled analysis of data from four studies. Lancet 2016;388:465-75.

5. Matsushita K, Coresh J, Sang Y, et al. Estimated glomerular filtration rate and albuminuria for prediction of cardiovascular outcomes: a collaborative meta-analysis of individual participant data. Lancet Diabetes Endocrinol 2015;3:514-25.

6. Blood Pressure Lowering Treatment Trialists' Collaboration. Blood pressure-lowering treatment based on cardiovascular risk: a metaanalysis of individual patient data. Lancet 2014;384:591-8.

7. Lu Y, Hajifathalian K, Ezzati M, et al. Metabolic mediators of the effects of body-mass index, overweight, and obesity on coronary heart disease and stroke: a pooled analysis of 97 prospective cohorts with 1.8 million participants. Lancet 2014;383:970-83.

8. Wilson PW, D'Agostino RB, Levy D, et al. Prediction of coronary heart disease using risk factor categories. Circulation 1998;97:1837-47.

9. Stamler J, Vaccaro O, Neaton JD, et al. Diabetes, other risk factors, and 12-yr cardiovascular mortality for men screened in the Multiple Risk Factor Intervention Trial. Diabetes Care 1993;16:434-44.

10. Haffner SM, Lehto S, Rönnemaa T, et al. Mortality from coronary heart disease in subjects with type 2 diabetes and in nondiabetic subjects with and without prior myocardial infarction. N Engl J Med 1998;339:229-34.

11. Bartnik M, Norhammar A, Rydén L. Hyperglycaemia and cardiovascular disease. J Intern Med 2007;262:145-56.

12. Goff DC, Gerstein HC, Ginsberg HN, et al. Prevention of cardiovascular disease in persons with type 2 diabetes mellitus: current knowledge and rationale for the Action to Control Cardiovascular Risk in Diabetes (ACCORD) trial. Am J Cardiol 2007;99:S4-S20.

13. Peters SA, Huxley RR, Woodward M. Diabetes as risk factor for incident coronary heart disease in women compared with men: a systematic review and meta-analysis of 64 cohorts including 858,507 individuals and 28,203 coronary events. Diabetologia 2014;57:1542-51.

14. Peters SA, Huxley RR, Woodward M. Diabetes as a risk factor for stroke in women compared with men: a systematic review and metaanalysis of 64 cohorts, including 775,385 individuals and 12,539 strokes. Lancet 2014;383:1973-80.

15. Walden CE, Knopp RH, Wahl PW, et al. Sex differences in the effect of diabetes mellitus on lipoprotein triglyceride and cholesterol concentrations. N Engl J Med 1984;311:953-9.

16. Stroup DF, Berlin JA, Morton SC, et al. Meta-analysis of observational studies in epidemiology: a proposal for reporting. Meta-analysis Of Observational Studies in Epidemiology (MOOSE) group. JAMA 2000;283:2008-12.

17 Wells G, Shea B, O' Connell D. The Newcastle-Ottawa Scale (NOS) for assessing the quality of nonrandomised studies in meta-analyses. Ottawa (ON): Ottawa Hospital Research Institute, 2009.

18. DerSimonian R, Laird N. Meta-analysis in clinical trials. Control Clin Trials 1986;7:177-88.

19. Ades AE, Lu G, Higgins JP. The interpretation of randomeffects meta-analysis in decision models. Med Decis Making 2005;25:646-54.

20. Woodward M. Epidemiology: study design and data analysis. 2nd edn. Boca Raton, FL, USA: Chapman and Hall/CRC, 2005.

21 Deeks JJ, Higgins JPT, Altman DG. Analyzing data and undertaking meta-analyses. In: Higgins J, Green S, eds. Cochrane Handbook for Systematic Reviews of Interventions 5.0.1. Oxford, UK: The Cochrane Collaboration, 2008.

22. Higgins JP, Thompson SG, Deeks JJ, et al. Measuring inconsistency in meta-analyses. BMJ 2003;327:557-60.

23. Tobias A. Assessing the influence of a single study in meta-analysis. Stata Tech Bull 1999;47:15-17.

24. Egger M, Davey Smith G, Schneider M, et al. Bias in meta-analysis detected by a simple, graphical test. BMJ 1997;315:629-34.

25. Begg CB, Mazumdar M. Operating characteristics of a rank correlation test for publication bias. Biometrics 1994;50:1088-101.

26. Kleinman JC, Donahue RP, Harris MI, et al. Mortality among diabetics in a national sample. Am J Epidemiol 1988;128:389-401.

27. Barrett-Connor E, Khaw KT. Diabetes mellitus: an independent risk factor for stroke? Am J Epidemiol 1988;128:116-23. 
28. the atherosclerosis risk in communities (ARIC) study: design and objectives. Am J Epidemiol 1989;129:687-702.

29. Fraser GE, Strahan TM, Sabaté J, et al. Effects of traditional coronary risk factors on rates of incident coronary events in a low-risk population. The Adventist Health Study. Circulation 1992;86:406-13.

30. Sievers ML, Nelson RG, Knowler WC, et al. Impact of NIDDM on mortality and causes of death in Pima Indians. Diabetes Care 1992;15:1541-9.

31. Seeman T, Mendes de Leon C, Berkman L, et al. Risk factors for coronary heart disease among older men and women: a prospective study of community-dwelling elderly. Am J Epidemiol 1993;138:1037-49.

32. Keil JE, Sutherland SE, Knapp RG, et al. Mortality rates and risk factors for coronary disease in black as compared with white men and women. N Engl J Med 1993;329:73-8.

33. Plan and operation of the Third National Health and Nutrition Examination Survey, 1988-94. Series 1: programs and collection procedures. Vital Health Stat 1 1994;11994:1-407.

34. Simons LA, Friedlander Y, McCallum J, et al. Risk factors for coronary heart disease in the prospective Dubbo Study of Australian elderly. Atherosclerosis 1995;117:107-18.

35. Collins VR, Dowse GK, Ram P, et al. Non-insulin-dependent diabetes and 11-year mortality in Asian Indian and Melanesian Fijians. Diabet Med 1996;13:125-32.

36. Nilsson PM, Johansson SE, Sundquist J. Low educational status is a risk factor for mortality among diabetic people. Diabet Med 1998;15:213-9.

37. Imazu M, Sumii K, Yamamoto $\mathrm{H}$, et al. Influence of type 2 diabetes mellitus on cardiovascular disease mortality: findings from the Hawaii-Los Angeles-Hiroshima study. Diabetes Res Clin Pract 2002;57:61-9.

38. Jónsdóttir LS, Sigfússon N, Gudnason V, et al. Do lipids, blood pressure, diabetes, and smoking confer equal risk of myocardial infarction in women as in men? The Reykjavik Study. J Cardiovasc Risk 2002;9:67-76.

39. Woodward M, Barzi F, Martiniuk A, et al. Cohort profile: the Asia Pacific Cohort Studies Collaboration. Int J Epidemiol 2006;35:1412-6.

40. Natarajan S, Liao Y, Cao G, et al. Sex differences in risk for coronary heart disease mortality associated with diabetes and established coronary heart disease. Arch Intern Med 2003;163:1735-40.

41. Iso $\mathrm{H}$, Imano $\mathrm{H}$, Kitamura $\mathrm{A}$, et al. Type 2 diabetes and risk of nonembolic ischaemic stroke in Japanese men and women. Diabetologia 2004;47:2137-44.

42. Whiteley L, Padmanabhan S, Hole D, et al. Should diabetes be considered a coronary heart disease risk equivalent?: results from 25 years of follow-up in the Renfrew and Paisley survey. Diabetes Care 2005;28:1588-93.
43. Hu G, Jousilahti P, Qiao Q, et al. Sex differences in cardiovascular and total mortality among diabetic and non-diabetic individuals with or without history of myocardial infarction. Diabetologia 2005;48:856-61.

44. Lee ET, Howard BV, Wang W, et al. Prediction of coronary heart disease in a population with high prevalence of diabetes and albuminuria: the Strong Heart Study. Circulation 2006;113:2897-905.

45. Najarian RM, Sullivan LM, Kannel WB, et al. Metabolic syndrome compared with type 2 diabetes mellitus as a risk factor for stroke: the Framingham Offspring Study. Arch Intern Med 2006;166:106-11.

46. Hunt KJ, Williams K, Hazuda HP, et al. The metabolic syndrome and the impact of diabetes on coronary heart disease mortality in women and men: the San Antonio Heart Study. Ann Epidemiol 2007:17:870-7.

47. Woodward M, Brindle P, Tunstall-Pedoe H; SIGN group on risk estimation. Adding social deprivation and family history to cardiovascular risk assessment: the ASSIGN score from the Scottish Heart Health Extended Cohort (SHHEC). Heart 2007;93:172-6.

48. Myint PK, Sinha S, Luben RN, et al. Risk factors for first-ever stroke in the EPIC-Norfolk prospective population-based study. Eur $J$ Cardiovasc Prev Rehabil 2008;15:663-9.

49. Oba S, Nagata C, Nakamura K, et al. Self-reported diabetes mellitus and risk of mortality from all causes, cardiovascular disease, and cancer in Takayama: a population-based prospective cohort study in Japan. J Epidemiol 2008;18:197-203.

50. Hyvärinen M, Tuomilehto J, Laatikainen $\mathrm{T}$, et al. The impact of diabetes on coronary heart disease differs from that on ischaemic stroke with regard to the gender. Cardiovasc Diabetol 2009;8:17.

51. Doi Y, Ninomiya T, Hata J, et al. Impact of glucose tolerance status on development of ischemic stroke and coronary heart disease in a general Japanese population: the Hisayama study. Stroke 2010;41:203-9.

52. Cui R, Iso H, Yamagishi K, et al. Diabetes mellitus and risk of stroke and its subtypes among Japanese: the Japan public health center study. Stroke 2011;42:2611-4.

53. Madssen E, Vatten L, Nilsen TI, et al. Abnormal glucose regulation and gender-specific risk of fatal coronary artery disease in the HUNT 1 study. Scand Cardiovasc J 2012;46:219-25.

54. Icks $A$, Claessen $\mathrm{H}$, Kvitkina $\mathrm{T}$, et al. Incidence and relative risk of stroke in the diabetic and the non-diabetic population between 1998 and 2014: A community-based stroke register. PLoS One 2017;12:e0188306.

55. Matsunaga $\mathrm{M}$, Yatsuya $\mathrm{H}$, Iso $\mathrm{H}$, et al. Similarities and differences between coronary heart disease and stroke in the associations with cardiovascular risk factors: The Japan Collaborative Cohort Study. Atherosclerosis 2017;261:124-30. 